\title{
Novelty detection in time series of ULF magnetic and electric components obtained from DEMETER satellite experiments above Samoa (29 September 2009) earthquake region
}

\author{
M. Akhoondzadeh \\ Remote Sensing Division, Surveying and Geomatics Engineering Department, University College of Engineering, \\ University of Tehran, Iran \\ Correspondence to: M. Akhoondzadeh (makhonz@ut.ac.ir)
}

Received: 8 March 2012 - Revised: 24 October 2012 - Accepted: 5 December 2012 - Published: 9 January 2013

\begin{abstract}
Using ULF (ultra low frequency) measurements of magnetometer and ICE (Instrument Champ Electrique) experiments on board the DEMETER satellite, possible irregularities in ULF magnetic and electric components have been surveyed in the vicinity of Samoa (29 September 2009) earthquake region. The data used in this paper cover the period from 1 August 2009 to 11 October 2009. The anomalous variations in magnetic components $\left(B_{x}, B_{y}\right.$ and $\left.B_{z}\right)$ were clearly observed on 1 and 3 days before the event. It is seen that the periodic patterns of the magnetic components obviously changed prior to the earthquake. These unusual variations have been also observed in the variations of polarization index obtained from the magnetic components during the whole period at $\sim 10: 30$ and $\sim 22: 30 \mathrm{LT}$. It is concluded that the polarization exhibits an apparent increase on 1 and 3 days preceding the earthquake. These observed unusual disturbances in ULF magnetic components were acknowledged using the detected perturbations in ULF electric components $\left(E_{x}, E_{y}\right.$ and $\left.E_{z}\right)$ in the geomagnetic coordinate system. Finally, the results reported in this paper were compared with previous results for this Samoa earthquake. Hence, the detected anomalies resulting from the magnetometer and ICE ULF waveforms in quiet geomagnetic conditions could be regarded as seismo-ionospheric precursors.
\end{abstract}

\section{Introduction}

The pre-seismic perturbations in lithosphere, atmosphere and ionosphere without significant solar and geomagnetic disturbances are considered as earthquake precursors. The iono- spheric anomalies usually happen in the D-layer, E-layer and F-layer and may be observed 1 to 10 days prior to the earthquake and continue a few days afterward (Parrot, 1995; Liu et al., 2000; Hayakawa and Molchanov, 2002; Pulinets and Boyarchuk, 2004; Akhoondzadeh, 2011).

Daily variations of the ionosphere depend on season, geographic location and other unknown parameters (thermospheric winds, traveling ionospheric disturbances). Moreover, the ionospheric parameters are affected by solar geophysical conditions and geomagnetic storms, especially in the equatorial and polar regions. Therefore, the measured plasma parameters may display variations in absence of seismic activity. Consequently, to discriminate the seismo-ionospheric perturbations from the geomagnetic disturbances, the geomagnetic indices $D_{\text {st }}$ and $K_{p}$ should be checked.

The study on pre-seismic ULF emissions started in the early 1990s. During seismic activity the ULF waves can propagate up to the Earth's surface with small attenuation. This is the most important advantage of seismic ULF emissions (Chmyrev et al., 1989, Fraser-Smith et al., 1990; Molchanov and Hayakawa, 1995; Hayakawa and Hattori, 2004; Sorokin et al., 2006; Hayakawa and Hattori, 2007). Chmyrev et al. (1989) presented the data on quasistatic electric fields and hydromagnetic waves in the frequency range $0.1-8 \mathrm{~Hz}$ detected by the Intercosmos-Bulgaria-1300 satellite over the earthquake zone. Recently, various groundbased observations have shown the possibility of ULF electromagnetic disturbances generation by earthquake preparation processes. Concerning ULF variations, for the first time magnetic field variation (Chmyrev et al., 1989) and electron

Published by Copernicus Publications on behalf of the European Geosciences Union. 

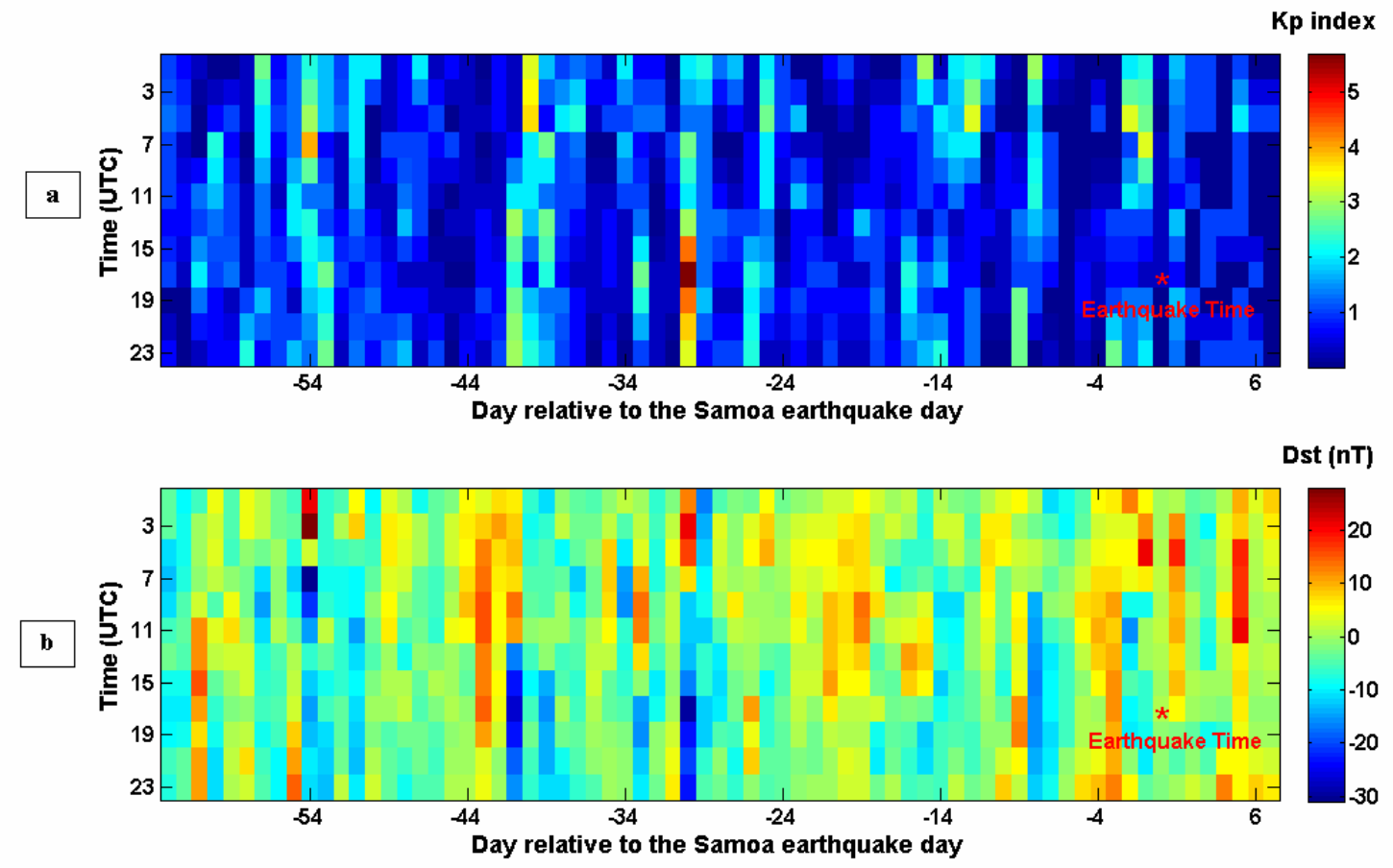

Fig. 1. Results of analysis for the Samoa earthquake (29 September 2009) from 28 July to 7 October 2009. The earthquake time is indicated by an asterisk. The X-axis represents the day relative to the earthquake day. The Y-axis represents the time UTC (LT $=\mathrm{UTC}-11: 00$ ). (a) Variations of $K_{p}$ geomagnetic index. (b) Variations of $D_{\text {st }}$ geomagnetic index.

number density fluctuations (Chmyrev et al., 1997) in ULF diapason related to seismic events had been revealed by direct measurements in the ionosphere. A model of these phenomena, estimation of observed parameters and its comparison with experimental data were performed by Sorokin et al. (1998).

Satellite measurements, due to their vast coverage of the seismic zones, along with other sources of information are considered suitable means for earthquake study. However, there are in general a limited number of studies on the possible relation of ULF waves in the upper ionosphere with earthquakes using satellite data. To this purpose, this study used DEMETER satellite data to investigate variations of ULF magnetic and electric components associated with the 29 September 2009 Samoa earthquake.

The French micro-satellite DEMETER (Detection of Electromagnetic Emissions Transmitted from Earthquake Regions) was launched on 29 June 2004 with the main scientific objective to detect anomalous variations of electromagnetic waves in different frequency ranges (DC/ULF: 0$15 \mathrm{~Hz}, \mathrm{ELF}: 15 \mathrm{~Hz}-1 \mathrm{kHz}, \mathrm{VLF}: 15 \mathrm{~Hz}-17.4 \mathrm{kHz}$ and HF: $10 \mathrm{kHz}-3.175 \mathrm{MHz}$ ), particle fluxes and thermal plasma parameters that could be related to seismic activity. Its threeaxes magnetometer (MAG) developed in the AOCS (attitude and orbit of satellite) system measures magnetic components in the ULF range. In the ULF range the time resolution of the electric waveform is $6.55360 \mathrm{~s}$ (Berthelier et al., 2006). The orbit of DEMETER is polar, sun-synchronous, and circular with a low altitude $(\sim 660 \mathrm{~km})$. The satellite provides a nearly continuous survey of the plasma, waves and energetic particles by different experiments at 10:30 and 22:30 LT. There are two modes of operation: (i) a survey mode to record low bit rate data all around the Earth at invariant latitudes less than $\sim 65^{\circ}$, and (ii) a burst mode to record high bit rate data above seismic regions.

\section{Observations}

This case study is focused on an earthquake which occurred in the Samoa Islands $\left(15.49^{\circ} \mathrm{S}, 172.10^{\circ} \mathrm{W}\right.$, Focal depth $18.0 \mathrm{~km}$ ) with a magnitude of $M_{\mathrm{w}}=8.1$ on 29 September 2009 at 17:48:10.99 UTC; (LT =UTC-11).

Figure 1a and b illustrate, respectively, the variations of $K_{p}$ and $D_{\text {st }}$ indices (http://spider.ngdc.noaa.gov) that were relatively quiet during days prior to the earthquake. The $K_{p}$ index shows a sudden magnetic activity on 30 August 2009, 30 days before the earthquake from 14:00 to 24:00 UTC.

Optimum distance between the satellite and the earthquake epicenter was selected in terms of DEMETER satellite altitude and earthquake zone radius. The radius of seismic area can be estimated using the Dobrovolsky formula $R=10^{0.43 M}$ where $R$ is the radius of the earthquake preparation zone, and $M$ is the earthquake magnitude 


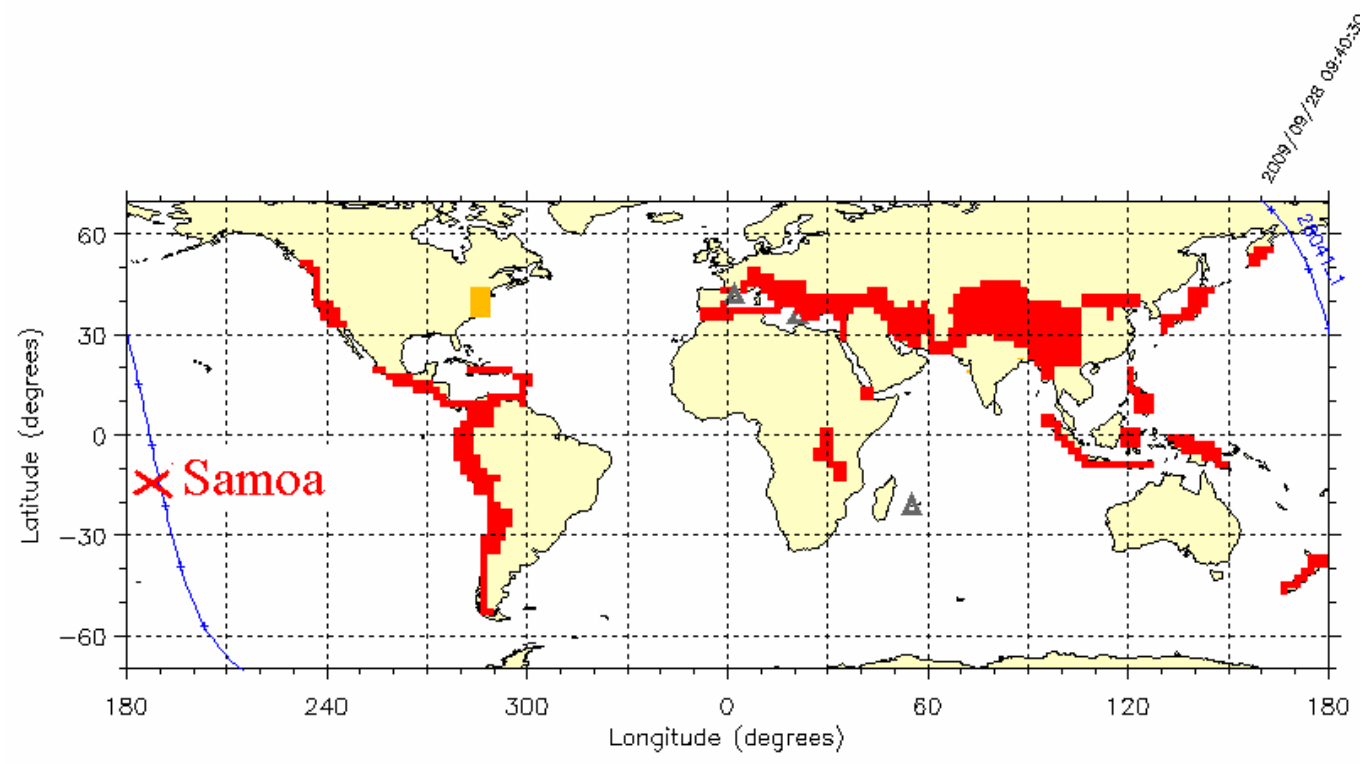

Fig. 2. Trace of the orbit number 28041.1. on 28 September 2009 between 09:02:30 and 09:40:59 LT, above the Samoa seismic region. The earthquake epicenter is indicated by a red cross at $15.49^{\circ} \mathrm{S}, 172.10^{\circ} \mathrm{W}$.
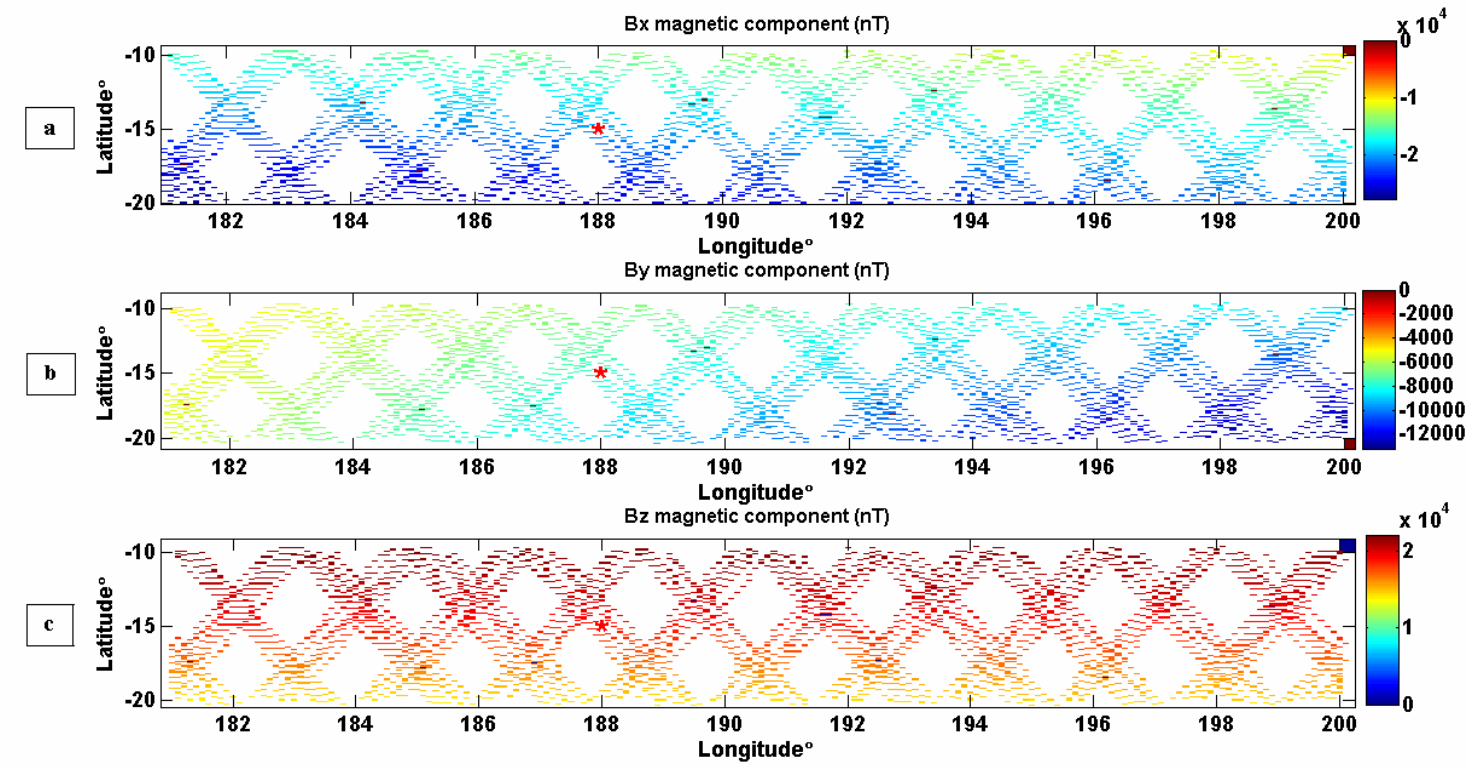

Fig. 3. Panels (a) through (c) represent the geographic variations of the magnetic components $B_{x}, B_{y}$ and $B_{z}$, respectively, for the Samoa earthquake (29 September 2009) from 1 August to 31 October 2009 . The earthquake epicenter is indicated by a red asterisk at $15.49^{\circ} \mathrm{S}$, $172.10^{\circ} \mathrm{W}$.

(Dobrovolsky et al., 1979). To take into account this distance, data have been selected when the satellite orbits are at $\pm 10^{\circ}$ in longitude and $\pm 2^{\circ}$ in latitude from the epicenter during the studied dates. Figure 2 shows the trace of the orbit number 28041.1. on 28 September 2009 between 09:02:30 and 09:40:59 LT, above the Samoa seismic region.
Panels a through c in Fig. 3 represent the geographic variations of the magnetic components $B_{x}, B_{y}$ and $B_{z}$, respectively, for the Samoa earthquake (29 September 2009) from 1 August to 31 October 2009. The earthquake epicenter is indicated by a red asterisk at $15.49^{\circ} \mathrm{S}, 172.10^{\circ} \mathrm{W}$. 

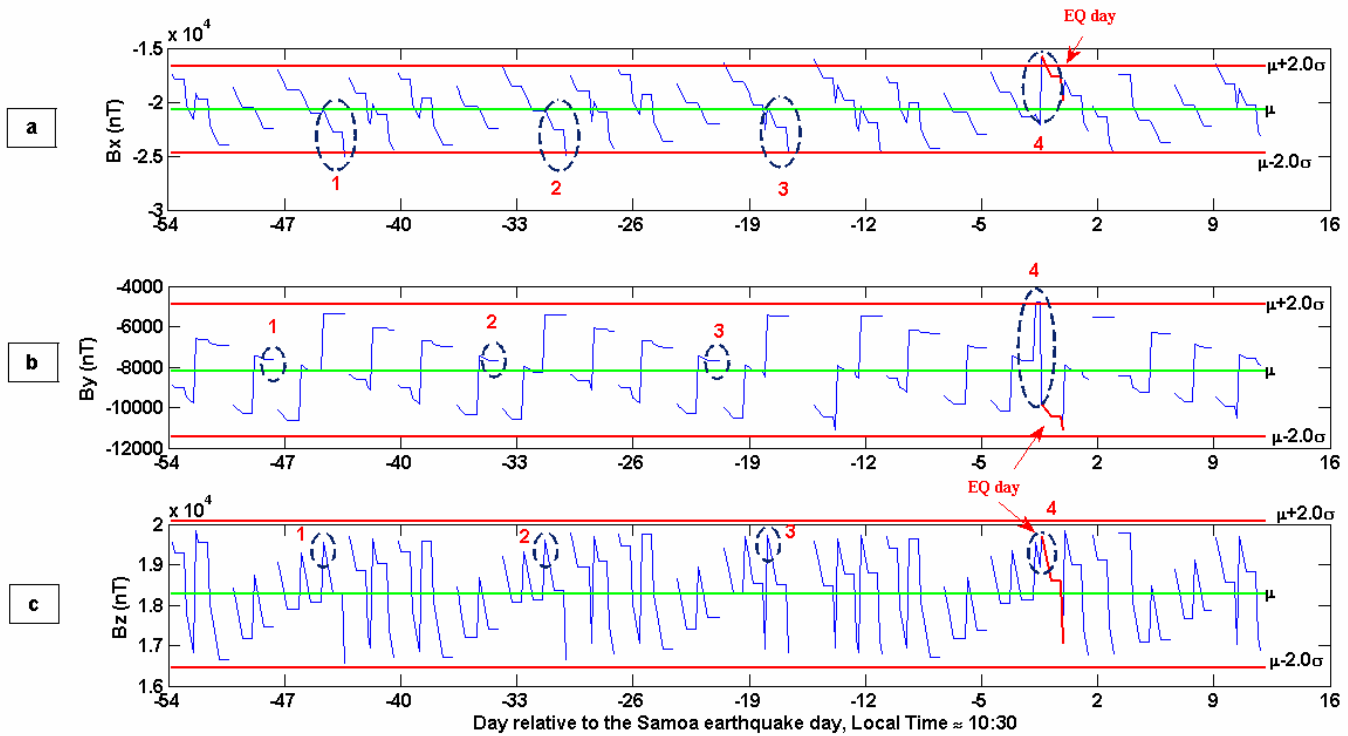

Fig. 4. Results of DEMETER data analysis for the Samoa earthquake (29 September 2009) from 5 August to 11 October 2009 at $\sim 10: 30$ LT. Due to the operation of satellite in passive mode, several gaps are observed. The red horizontal lines indicate the higher and lower bounds $(\mu \pm 2.0 \times \sigma)$. The green horizontal line indicates the mean value $(\mu)$. The earthquake event is represented in red. The dotted ellipsoids 1 through 4 represent the variations of a selected section of the time series. The ULF magnetic components were calculated in geographic coordinate system. The panels (a) through (c) represent the ULF magnetic waveforms in directions of X, Y and Z, respectively.

Figure 4 represents the temporal evolutions of the magnetic components $\left(B_{x}, B_{y}\right.$ and $\left.B_{z}\right)$ from about 54 days before to 11 days after the event at $\sim 10: 30$ LT. Due to the operation of satellite in passive mode, several time gaps are observed during the studied time intervals. The earthquake day is represented in red. The $\mathrm{X}$-axis represents the days related to event whereas the Y-axis shows the wave amplitude $(n T)$. The red horizontal lines show the higher and lower bounds $(\mu \pm 2.0 \times \sigma)$. The green horizontal line represents the mean value $(\mu)$. The dotted ellipsoids 1 through 4 in each panel represent the variations of a selected section of the time series of the ULF magnetic components. Figure 4a obviously indicates that the pattern of the selected section suddenly changes on 1 day before the earthquake with the values of the $B_{x}$ magnetic component increasing to $-15400 n T$ and exceeding the upper bound $(\mu+2.0 \times \sigma)$. The unusual changes in the periodic patterns of the selected sections in the time series of $B_{y}$ and $B_{z}$ magnetic components (the dotted ellipsoids 1 through 4 in Figs. $4 \mathrm{~b}$ and c) acknowledge the detected anomalous variations in $B_{x}$ component on 1 day before the earthquake.

Figure 5 illustrates the variations of the magnetic components $\left(B_{x}, B_{y}\right.$ and $\left.B_{z}\right)$ from about 59 days before to 11 days after the earthquake at $\sim 22: 30$ LT. Figure 5a represents the values of the $B_{x}$ magnetic component, which exceed the upper bound on 3 days preceding the event. It can be also seen that the selected section in the time series has similar variations in the dotted ellipsoids 1 through 3 , but it suddenly changes in the dotted ellipsoid 4 . The results obtained from the analysis of the $B_{y}$ and $B_{z}$ magnetic components at night are consistent with the results for the $B_{x}$ magnetic component. The unusual changes in the selected patterns are recognized by the visual inspection of the the $B_{y}$ and $B_{z}$ magnetic components variations. (The dotted ellipsoids 1 through 4 in Figs. $5 b$ and $c)$.

Figures $6 \mathrm{a}$ and $\mathrm{b}$ represent the temporal evolutions of the polarization index during the studied period at $\sim 10: 30$ and $\sim 22: 30$ LT, respectively. Polarization method is based on the measurement of the ratio of the vertical magnetic field component $\left(B_{z}\right)$ to the horizontal magnetic field component $\left(\sqrt{B_{x}+B_{y}}\right)$. It can be seen from this figure that a certain enhancement is detected in the polarization plots on 1 day before the earthquake at $\sim 10: 30$ LT and also on 3 days prior to the event at $\sim 22: 30$ LT. Figure 6 a shows the anomalous changes in the selected section in the dotted ellipsoid 4 . It suddenly changes on 1 day preceding the event and exceeds the upper bound. Also, Fig. $6 \mathrm{~b}$ indicates that the values of the polarization index exceed the upper bound on 3 days before the earthquake. The indices $K_{p}$ and $D_{\text {st }}$ did not show any significant changes before the earthquake, which means that the increase in polarization before the earthquake has nothing to do with the geomagnetic activity, but it could be associated with the earthquake.

Figures 7a, 8a and 9a illustrate the temporal evolutions of the wave forms of ULF electric components $\left(E_{x}, E_{y}\right.$ and $\left.E_{z}\right)$ measured by ICE experiment on board the DEMETER satellite close to the Samoa seismic region from about 54 days before to 11 days after events on 29 September 2009 at $\sim$ 10:30 LT. The time series of the ULF electric components 

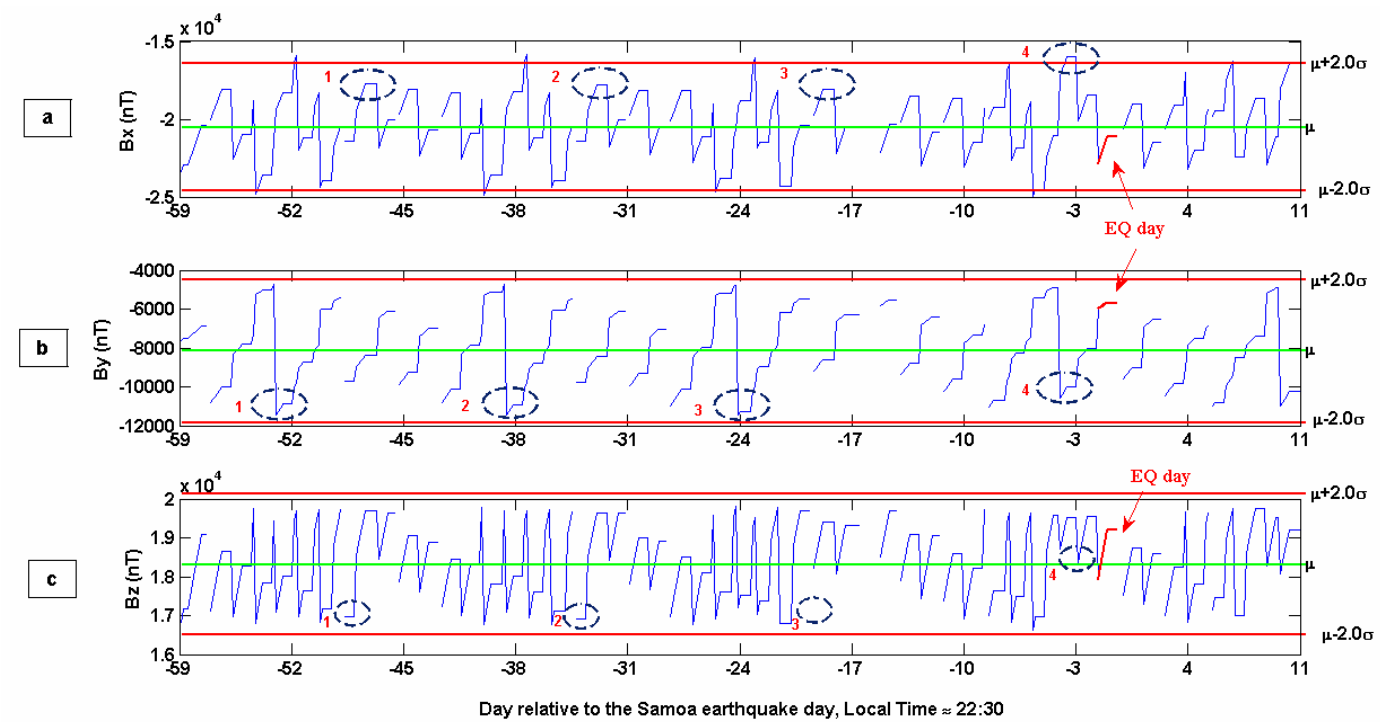

Fig. 5. Same as Fig. 4 but for local time at $\sim 22: 30$.
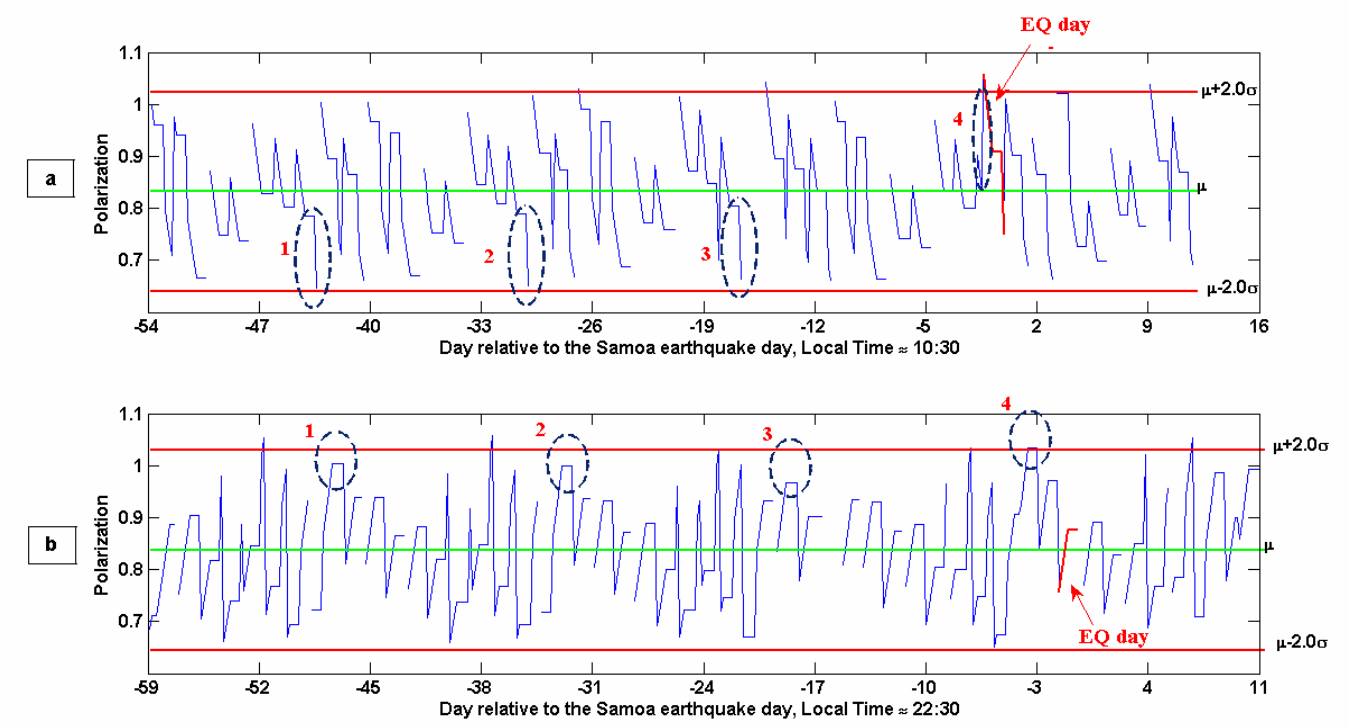

Fig. 6. Temporal evolutions of the polarization $\left(B_{z} / \sqrt{B_{x}+B_{y}}\right)$ obtained from the magnetic components at (a) $\sim 10: 30$ LT and (b) $\sim 22: 30$ LT.

$\left(E_{x}, E_{y}\right.$ and $E_{z}$ ) at $\sim 22: 30 \mathrm{LT}$ during the whole period from 2 August to 11 October 2009 is shown in Figs. 10a, 11a and 12a. The $\mathrm{X}$-axis represents the days related to event whereas the $\mathrm{Y}$-axis shows the wave amplitude $\left(\mathrm{mV} \mathrm{m}^{-1}\right)$. Discontinuities in the time series are associated with the satellite orbitography. As seen in the Figs. 7a through 12a, we cannot deduce noticeable unusual variations in ULF electric components prior to the studied earthquake.

Previous satellite observations have indicated that the average contact potential difference between spherical electrodes of similar size was typically a few tens of $\mathrm{mV}$. But in three-axis stabilized satellites such as DEMETER the contact potential differences between the sensors are difficult to correct. Owing to the relative stability in time of the surface potential of the sensor electrodes, small-scale quasi-ULF electric fields can be accurately measured as irregularities that arise mainly from the induced $\boldsymbol{V} \times \boldsymbol{B}_{\mathbf{0}}$ electric field (Berthlier, 2006). In order to clear up this uncertainty, using the components of the magnetic field model at the satellite point $\boldsymbol{B}_{0}(n T)$ and also the satellite velocity vector $\boldsymbol{V}\left(\mathrm{m} \mathrm{s}^{-1}\right)$, the $V \times B$ electric field vector was calculated for each ULF electric component (Figs. $7 \mathrm{~b}$ through $12 \mathrm{~b}$ ). By incorporation of $V \times B$ effect, the ULF electric components without induced $V \times B$ electric field were computed (Figs. 7c through 12c). 

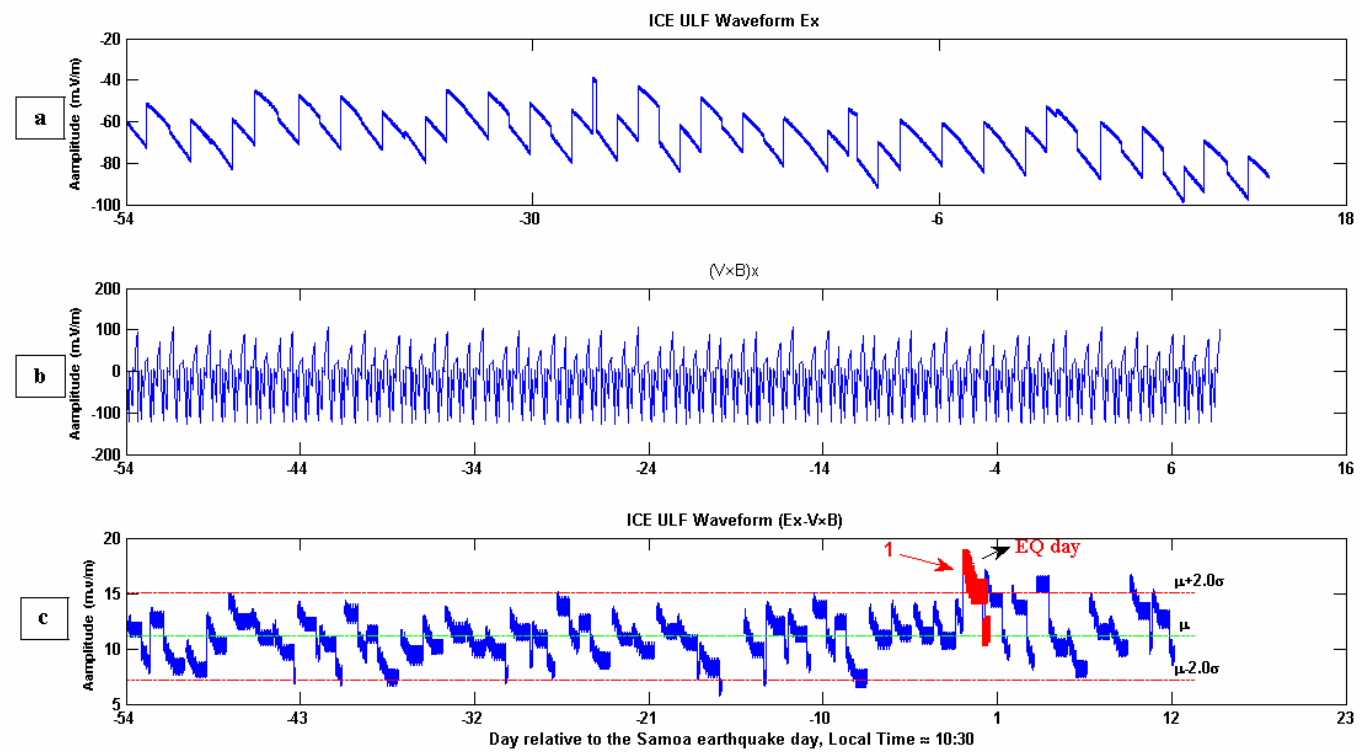

Fig. 7. Results of DEMETER data analysis for the Samoa earthquake (29 September 2009) from 5 August to 12 October 2009 at $\sim 10: 30$ LT. Due to the operation of satellite in passive mode several gaps are observed. The red horizontal lines indicate the higher and lower bounds $(\mu \pm 2.0 \times \sigma)$. The green horizontal line indicates the mean value $(\mu)$. The $\mathrm{X}$-axis represents the days related to the earthquake. The earthquake event is represented in red. ULF electric components were calculated in local geomagnetic coordinate system. (a) ICE ULF waveform in direction of X. (b) $V \times B$ electric field component in direction of X. (c) ICE ULF waveform without induced $V \times B$ electric field in direction of $\mathrm{X}$.
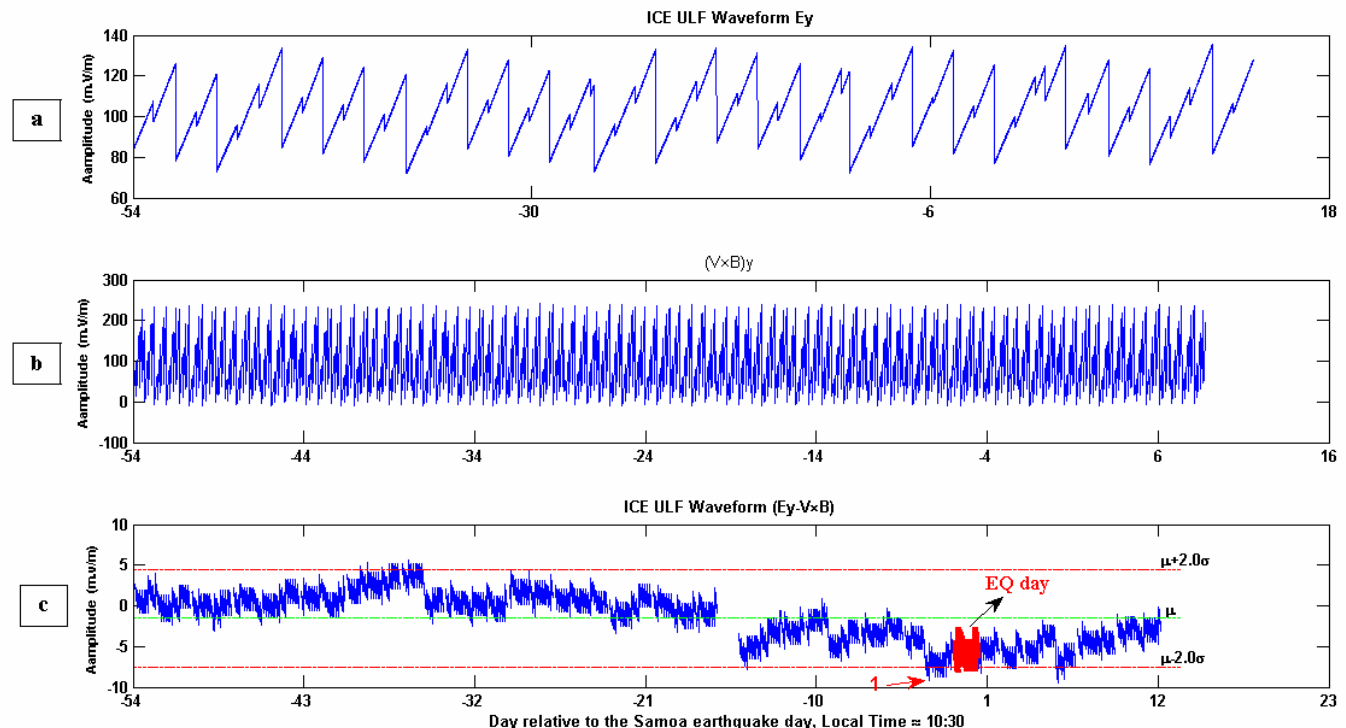

Fig. 8. Same as Fig. 7 but for ICE ULF waveform in direction of Y.

Figure 7c indicates that $E_{x}$ component has exceeded the upper bound on 1 day before the earthquake and this disturbed state for the 29 September 2009 Samoa earthquake reaches the maximum value by the order of $18.1\left(\mathrm{mV} \mathrm{m}^{-1}\right)$ 1 day before the earthquake at $\sim 10: 30$ LT (the first red ar- row in Fig. 7c). This effect was also confirmed by the $E_{y}$ fluctuations when it exceeded the lower bound by the order of $-9.1\left(\mathrm{mV} \mathrm{m}^{-1}\right)$ (the first red arrow in Fig. 8c) and also the sharp increase of $E_{z}$ component, 1 day before the earthquake $\left(58.2 \mathrm{mV} \mathrm{m}^{-1}\right)$ (the first red arrow in Fig. 9c). These 

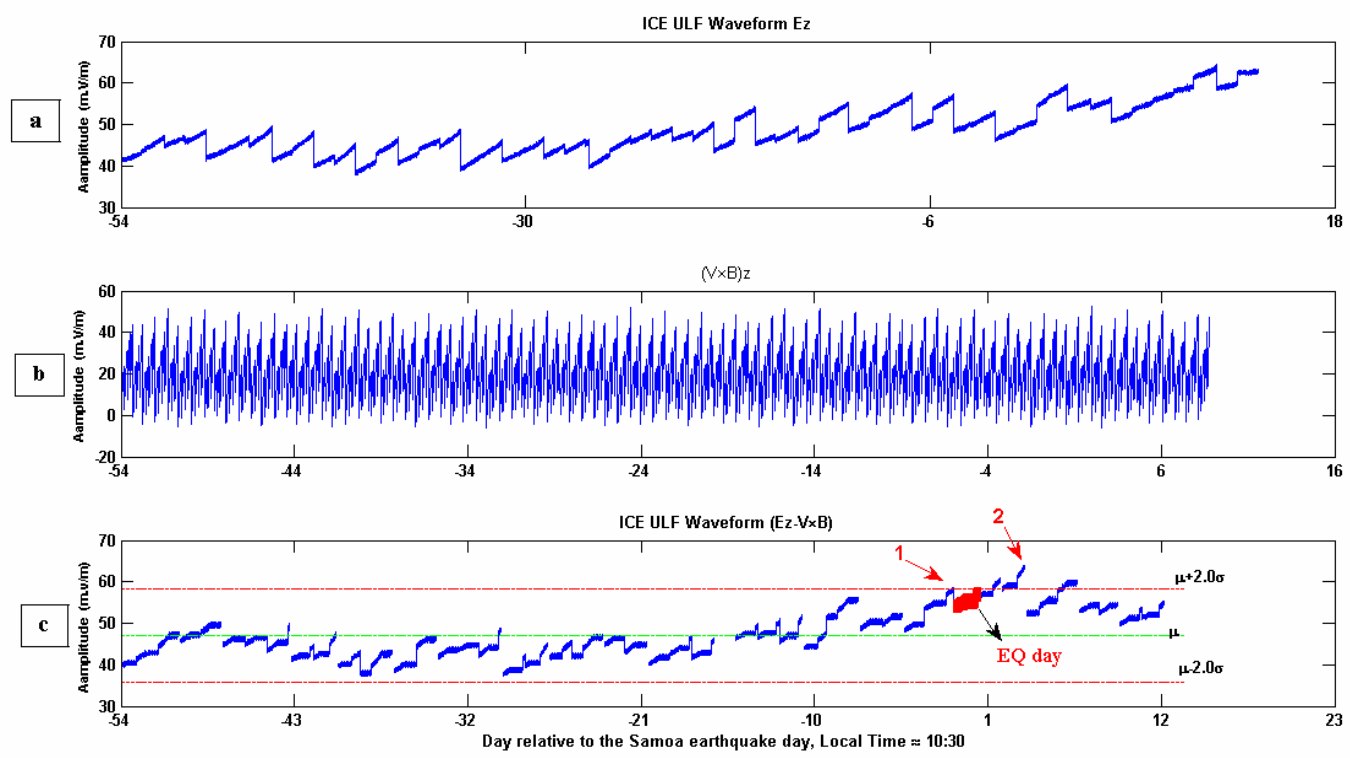

Fig. 9. Same as Fig. 7 but for ICE ULF waveform in direction of Z.
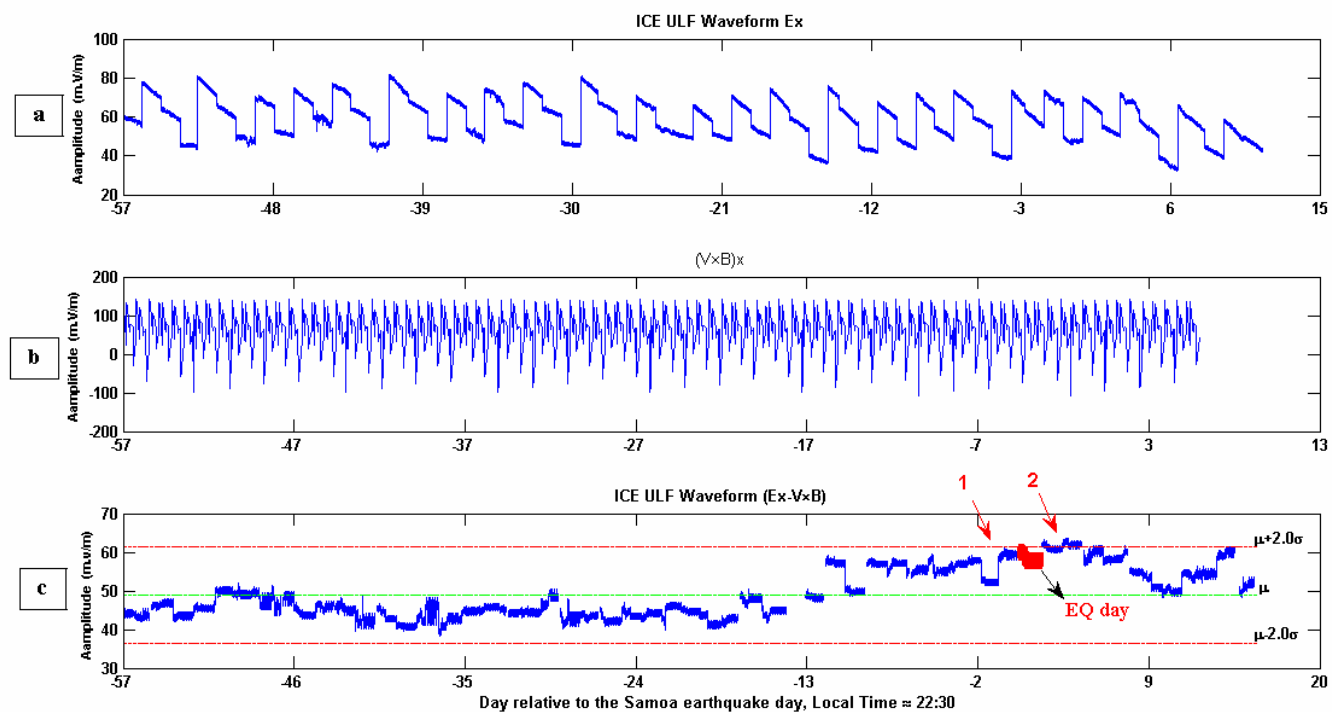

Fig. 10. Results of DEMETER data analysis for the Samoa earthquake (29 September 2009) from 2 August to 11 October 2009 at $\sim 22: 30$ LT. (a) ICE ULF waveform in direction of X. (b) $V \times B$ electric field component in direction of X. (c) ICE ULF waveform without induced $V \times B$ electric field in direction of $\mathrm{X}$.

disturbed states in the ULF components were also seen after the earthquake, which could be attributed to the earthquake post seismic activities (the second red arrow in Fig. 9c).

Figures $10 \mathrm{c}$ and $11 \mathrm{c}$ represent the unusual variations of $E_{x}$ and $E_{y}$ components on 1 day before the earthquake at $\sim 22: 30 \mathrm{LT}$ (the first red arrows in Fig. 10c and 11c). The $E_{x}$ component reaches the maximum value by the order of
$61\left(\mathrm{mV} \mathrm{m}^{-1}\right) 1$ day before the earthquake. The value of $E_{y}$ component exceeded the upper bound by the order of 27.2 $\left(\mathrm{mV} \mathrm{m}^{-1}\right)$ on 1 day before the earthquake at $\sim 22: 30 \mathrm{LT}$. These anomalous variations in the ULF components were also detected after the earthquake (the second red arrows in Figs. 10c and 11c). Plots of $E_{z}$ component have not exhibited 
Table 1. The observed anomalies before the 29 September 2009 Samoa earthquake (Akhoondzadeh et al., 2010a, b).

\begin{tabular}{|c|c|c|}
\hline Precursor & $\begin{array}{l}\text { Date of } \\
\text { observed } \\
\text { anomaly }\end{array}$ & $\begin{array}{l}\text { Deviation } \\
\text { value } \\
(D x)\end{array}$ \\
\hline TEC & $\begin{array}{l}28 \text { Sep } \\
28 \text { Sep } \\
28 \text { Sep } \\
28 \text { Sep } \\
27 \text { Sep } \\
27 \text { Sep } \\
26 \text { Sep } \\
25 \text { Sep } \\
25 \text { Sep } \\
24 \text { Sep }\end{array}$ & $\begin{array}{l}+2.78 \\
+3.73 \\
+3.38 \\
+2.63 \\
+2.73 \\
+2.54 \\
+2.91 \\
+2.60 \\
+3.07 \\
+2.55\end{array}$ \\
\hline $\begin{array}{l}\text { Electron Temperature } \\
\mathrm{O}^{+} \text {Density } \\
\text { Total Ion Density } \\
\text { Ion Density } \\
\text { Total Ion Density } \\
\mathrm{O}^{+} \text {Density } \\
\text { Ion Temperature } \\
\text { Electron Density } \\
\text { Electron Temperature } \\
\text { Electron Density } \\
\text { Ion Density } \\
\text { Total Ion Density } \\
\mathrm{O}^{+} \text {Density } \\
\mathrm{O}^{+} \text {Density } \\
\text { Total Ion Density } \\
\text { Electron Density } \\
\text { Ion Density }\end{array}$ & $\begin{array}{l}27 \text { Sep } \\
26 \text { Sep } \\
26 \text { Sep } \\
26 \text { Sep } \\
25 \text { Sep } \\
25 \text { Sep } \\
25 \text { Sep } \\
25 \text { Sep } \\
25 \text { Sep } \\
24 \text { Sep } \\
23 \text { Sep } \\
21 \text { Sep } \\
21 \text { Sep } \\
21 \text { Sep } \\
21 \text { Sep } \\
21 \text { Sep } \\
18 \text { Sep }\end{array}$ & $\begin{array}{l}+3.24 \\
+2.12 \\
+2.08 \\
+2.28 \\
+3.0 \\
+3.18 \\
-2.87 \\
+3.01 \\
-1.82 \\
+2.89 \\
+1.96 \\
+1.65 \\
+2.24 \\
+2.07 \\
+2.04 \\
+2.8 \\
+2.07\end{array}$ \\
\hline $\begin{array}{l}\text { The intense appearance of NPM } \\
\text { transmitter waves in the VLF } \\
\text { electric spectrogram }\end{array}$ & $21 \mathrm{Sep}$ & $>2.2$ \\
\hline $\begin{array}{l}\text { The intense appearance of NPM } \\
\text { transmitter waves in the VLF } \\
\text { magnetic spectrogram }\end{array}$ & $21 \mathrm{Sep}$ & $>2.2$ \\
\hline $\begin{array}{l}\text { The attenuation of NPM trans- } \\
\text { mitter waves in the VLF electric } \\
\text { spectrogram }\end{array}$ & 24 Sep & $>2.2$ \\
\hline $\begin{array}{l}\text { The most appearance of har- } \\
\text { monic emissions above NPM } \\
\text { transmitter in the HF electric } \\
\text { spectrogram }\end{array}$ & 27 Sep & $>2.2$ \\
\hline $\begin{array}{l}\text { The intense appearance of har- } \\
\text { monic emissions above NPM } \\
\text { transmitter in the HF electric } \\
\text { spectrogram }\end{array}$ & $28 \mathrm{Sep}$ & $>2.2$ \\
\hline Sea surface temperature & $26 \mathrm{Sep}$ & 0.79 \\
\hline
\end{tabular}

any noticeable changes associated with the earthquake during the whole period at $\sim 22: 30 \mathrm{LT}$ (Fig. 12c).

\section{Discussion}

The mechanism of the ULF magnetic and electric field disturbances in the ionosphere prior to an earthquake is not clearly known. Several researchers have suggested an influence of DC electric field on the ionosphere above seismic regions (Chmyrev et al., 1989; Sorokin et al., 2006).

Zhang et al. (2011) proposed a coupling process among lithosphere-atmosphere-ionosphere (LAI), which might give a better understanding of the electromagnetic perturbations and plasma turbulences in the ionosphere. Due to the energy accumulation in seismic area, the number of microfractures increases, and gas and radioactive materials are emitted into the atmosphere (Zhang et al., 2011). In the earthquake preparation zone, water vapor goes into the atmosphere due to the increasing temperature and latent heat flux.

Recently, Akhoondzadeh et al. (2010a, b) have observed seismo-ionospheric anomalies using DEMETER IAP, ISL, ICE and IMSC experiments and also TEC data before the Samoa (29 September 2009) earthquake. Table 1 provides the observed anomalies before this Samoa earthquake. It is seen that the value of the sea surface temperature has exceeded the limited bounds by the order of 0.79 on 3 days before the event.

All of these unusual variations will consequently lead to seismic acoustic gravity wave (AGW), which will propagate and penetrate the lower ionosphere (Molchanov and Hayakawa, 2008; Zhang et al, 2011). When seismic AGW encounters the perturbations induced by the action of $E \times B$ and drift results from neutral wind in the atmosphere, they will interact with each other, resulting in irregularities in the ionosphere. During the process, the energy will be exchanged or transferred, and Joule heating will play an important role (Sorokin and Chmyrev, 1999; Zhang et al., 2011), depicted by the electron temperature increase of more than $1000 \mathrm{~K}$ (Zhang et al., 2011). The detected anomalies in electron and ion density and temperature reported by Akhoondzadeh et al. (2010a) acknowledge the results deduced from the mechanism proposed by Zhang et al. (2011).

The different observed anomalies in electric components can be explained based on another mechanism. The local geomagnetic coordinate system is defined versus the Earth magnetic field vector $\boldsymbol{B}_{\mathbf{0}}$ (Fig. 13). Origin $S$ is defined at the centre of the satellite; $Z_{B}$ axis is parallel to the $\boldsymbol{B}_{\mathbf{0}}$ field vector; $Y_{B}=\left(Z_{B} \wedge \boldsymbol{P} \boldsymbol{O} \boldsymbol{S}\right) /\left|Z_{B} \wedge \boldsymbol{P} \boldsymbol{O} \boldsymbol{S}\right|$ and $X_{B}=Y_{B} \wedge Z_{B}$ (located in the plane $\left[\boldsymbol{P O S}, \boldsymbol{B}_{\mathbf{0}}\right]$ (Lagoutte et al., 2006).

Among the observed pre-seismic anomalies in $E_{x}, E_{y}$ and $E_{z}$ components, the variations of the $E_{x}$ and $E_{y}$ components are noticeable. Pre-seismic electric field and its polarity cause the electrons in the F-layer to penetrate to lower layers and therefore to create anomaly in the ionospheric 

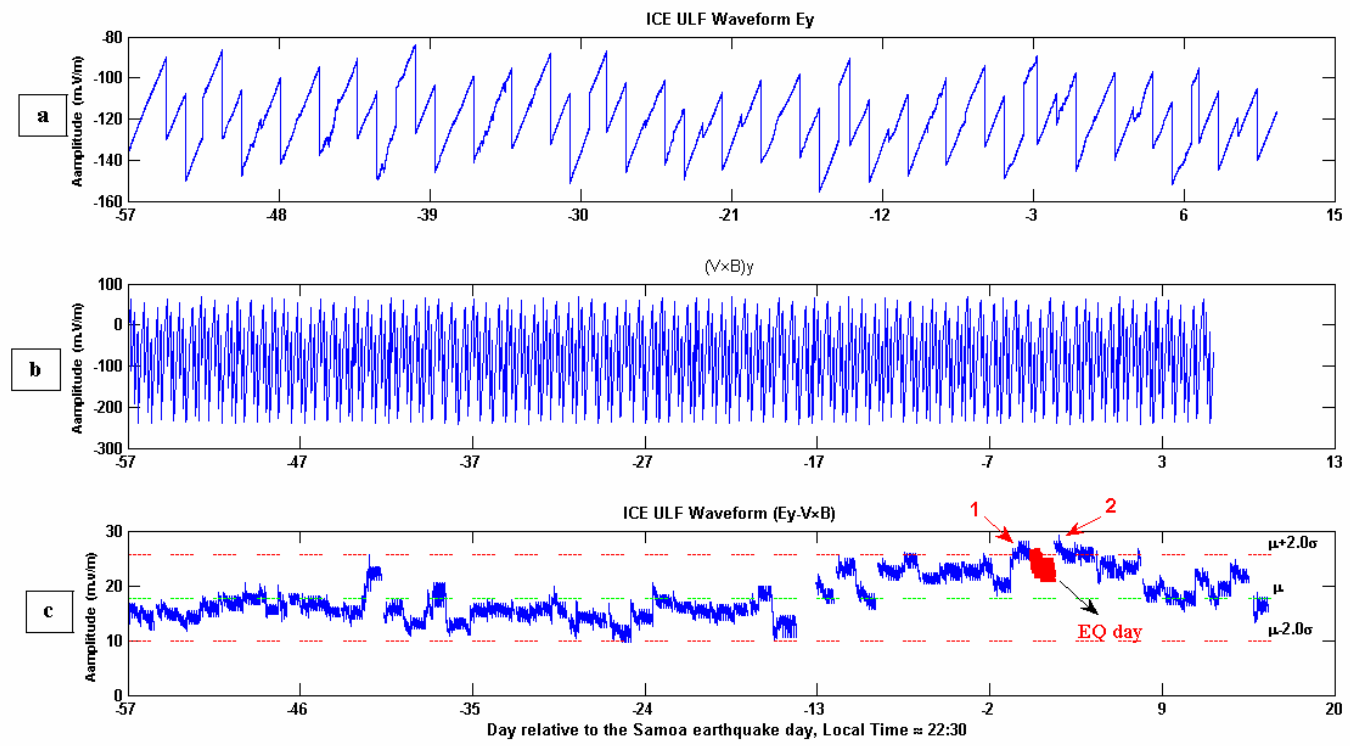

Fig. 11. Same as Fig. 10 but for ICE ULF waveform in direction of Y.
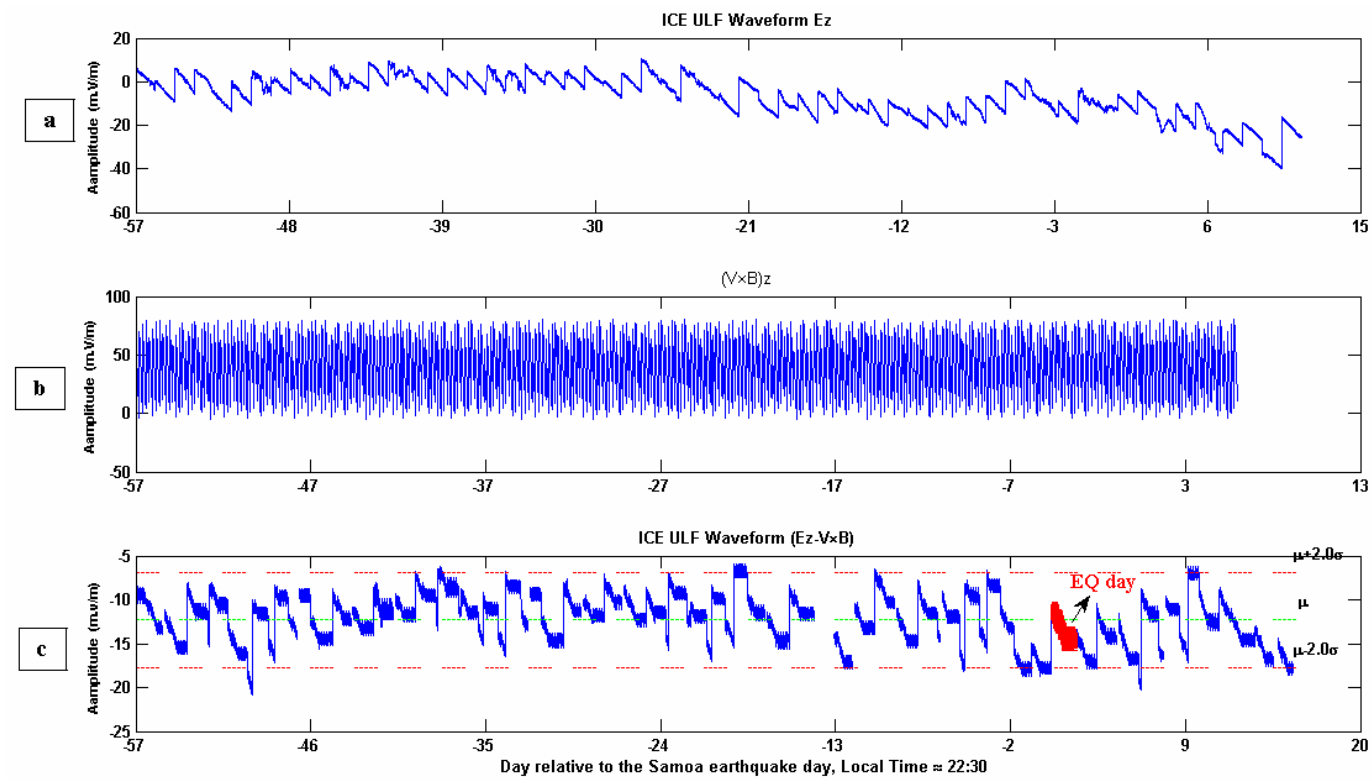

Fig. 12. Same as Fig. 10 but for ICE ULF waveform in direction of Z.

parameters. The thin layer of particles created before earthquakes due to ions radiation from the Earth has a main role in transferring electric field to above the atmosphere and then to the ionosphere. The penetration of this electric field to the ionosphere was first analytically calculated by Park and Dejnakarintra (1973) and then applied to the seismoelectromagnetic process by Kim et al. (1994) and Pulinets et al. (2000).

Sorokin et al. (2006) have indicated that external electric current in the lower atmosphere can lead to such redistribu- tion of conductivity current that resulted in ULF electric field increases up to $10 \mathrm{mV} \mathrm{m}^{-1}$ in the ionosphere. Due to conductivity anisotropy that appears at altitudes higher than $90 \mathrm{~km}$, the conductivity along the geomagnetic field lines can be considered infinite, but in directions perpendicular to the geomagnetic field lines the electric conductivity is much lower, which creates the possibility of forming longitudinal irregularities in the ionosphere. This zonal component leads to plasma density anomalies, which are indeed observed in the earthquake area (Pulinets, 2009). 


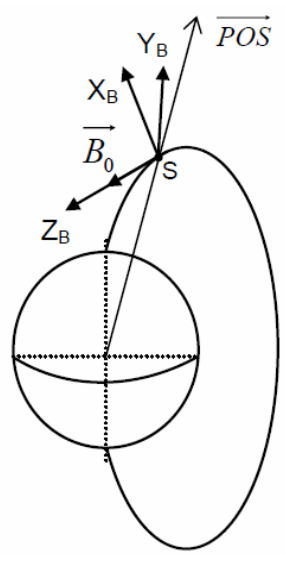

Fig. 13. The local geomagnetic coordinate system (Lagoutte et al., 2006).

Thanks to these hypotheses, the most anomalous variations along the $E_{x}$ and $E_{y}$ components are convincing. Based on the local geomagnetic coordinate system (Fig. 13), $E_{z}$ component is parallel to the $\boldsymbol{B}_{\mathbf{0}}$ magnetic vector and $E_{y}$ component is perpendicular to the geomagnetic field lines. Therefore the $E_{y}$ component of the ULF electric waveform appeared larger than the $\mathrm{Z}$ component in the ULF electric waveform.

\section{Conclusions}

In this paper, the DEMETER ICE ULF electric waveforms and also magnetometer data have been analyzed to detect seismo-ionospheric anomalies concerning a time period of 58 days before and 11 days after a strong earthquake that took place in Samoa on 29 September 2009.

One of the most interesting and promising results of this case study is the observed anomalies in the magnetic and electric components based on the proposed mechanisms by the mentioned researchers, a few days prior to the strong earthquake. Our results indicate that the highest intensity of pre-earthquake anomaly appeared within the time interval 1-3 days before this studied earthquake. Because geomagnetic activity was very quiet during the days prior to the earthquake, the detected anomalies can be interpreted as the pre-seismic ionospheric variations. The findings of this paper acknowledge the detected anomalies in different parameters (sea surface temperature, electron density, electron temperature, total ion density and TEC) before the 29 September 2009 Samoa earthquake (Akhoondzadeh et al., 2010a, b). The results of this paper are also promising for the short-term prediction in ULF magnetic and electric ranges but further investigation is required to obtain a more thorough, accurate regional model of quiet time for the ionosphere to discriminate seismic precursors from the background of normal daily variations.
Acknowledgements. This work was supported by the University of Tehran for MA. The author thanks J. J. Berthelier, the PI of ICE, for the use of the data and M. Parrot for his fruitful and constructive suggestions.

Edited by: M. E. Contadakis

Reviewed by: P. F. Biagi and two anonymous referees

\section{References}

Akhoondzadeh, M.: Comparative study of the earthquake precursors obtained from satellite data, $\mathrm{PhD}$ thesis, University of Tehran, Surveying and Geomatics Engineering Department, Remote Sensing Division, 2011.

Akhoondzadeh, M., Parrot, M., and Saradjian, M. R.: Electron and ion density variations before strong earthquakes $(M>6.0)$ using DEMETER and GPS data, Nat. Hazards Earth Syst. Sci., 10, $7-$ 18, doi:10.5194/nhess-10-7-2010, 2010a.

Akhoondzadeh, M., Parrot, M., and Saradjian, M. R.: Investigation of VLF and HF waves showing seismo-ionospheric anomalies induced by the 29 September 2009 Samoa earthquake $\left(M_{\mathrm{W}}=8.1\right)$, Nat. Hazards Earth Syst. Sci., 10, 1061-1067, doi:10.5194/nhess-10-1061-2010, 2010b.

Berthelier, J. J., Godefroy, M., Leblanc, F., Malingre, M., Menvielle, M., Lagoutte, D., Brochot, J. Y, Colin, F., Elie, F., Legendre, C., Zamora, P, Benoist, D., Chapuis, Y., Artru, J., and Pfaff, R.: ICE, the electric field experiment on DEMETER, Planet. Space Sci., 54, 456-471, 2006.

Chmyrev, V. M., Isaev, N. V., Bilichenko, S. V., and Stanev, G.: Observation by space-borne detectors of electric fields and hydromagnetic waves in the ionosphere over an earthquake centre, Phys. Earth Planet. Int., 57, 110-114, 1989.

Chmyrev, V. M., Isaev, N. V., Serebryakova, O. N., Sorokin, V. M., and Sobolev, Y. P.: Small - scale plasma inhomogeneities and correlated ELF emissions in the ionosphere over an earthquake region, J. Atmos. Solar-Terr. Phys., 59, 967-973, 1997.

Fraser-Smith, A. C., Bernardi, A., McGill, P. R., Ladd, M. E., Helliwell, R. A., and Villard Jr, O. G.: Low-frequency magnetic field measurements near the epicenter of the Ms 7.1 Loma Prieta earthquake, Geophys. Res. Lett., 17, 1465-1468, 1990.

Hayakawa, M. and Hattori, K.: ULF electromagnetics emissions associated with earthquakes: Review, Trans. Fundamentals and Materials, Special Issue on Electromagnetic Theory and its Application, 124, 1101-1108, 2004.

Hayakawa, M. and Hattori, K.: Monitoring of ULF (ultra-lowfrequency) Geomagnetic Variations Associated with Earthquakes, Sensors, 7, 1108-1122, 2007.

Hayakawa, M. and Molchanov, O. A.: Seismo- Electromagnetics: Lithosphere-Atmosphere-Ionosphere Coupling, Terra Scientific Publishing Co., Tokyo, 477, 2002.

Kim, V. P., Hegai, V. V., and Illich-Svitych, P. V.: On one possible ionospheric precursor of earthquakes, Phys. Solid Earth, 30, 223-226, 1994.

Lagoutte, D., Brochot, J. Y., de Carvalho, D., Madrias, L., and Parrot, M.: DEMETER Microsatellite Scientific Mission Center Data Product Description, DMT-SP-9-CM-6054-LPC, 2006.

Liu, J. Y., Chen, Y. I., Pulinets, S. A., Tsai, Y. B., and Chuo, Y. J.: Seismo-ionospheric signatures prior to $\mathrm{M} \geq 6.0$ 
Taiwan earthquakes, Geophys. Res. Lett., 27, 3113-3116, doi:10.1029/2000GL011395, 2000.

Molchanov, O. A. and Hayakawa, M.: Generation of ULF electromagnetic emissions by microfracturing, Geophys. Res. Lett., 22, 3091-3094, 1995.

Molchanov, O. A. and Hayakawa, M.: Seismo-electromagnetics and related phenomena: History and latest results, TERRAPUB, Tokyo, 190, 2008.

Park, C. G. and Dejnakarintra, M.: Penetration of thundercloud electric fields into the ionosphere and magnetosphere, 1. Middle and auroral latitudes, J. Geophys. Res., 84, 960-964, 1973.

Parrot, M.: Use of satellites to detect seismo-electromagnetic effects, Main phenomenological features of ionospheric precursors of strong earthquakes, Adv. Space Res., 15, 1337-1347, 1995.

Pulinets, S. A.: Physical mechanism of the vertical electric field generation over active tectonic faults, Adv. Space Res., 44, 767773, 2009.

Pulinets, S. A., Boyarchuk, K. A., Hegai, V. V., Kim, V. P., and Lomonosov, A. M.: Quasielectrostatic Model of AtmosphereThermosphere-Ionosphere Coupling, Adv. Space Res., 26, 12091218, 2000.
Pulinets, S. A. and Boyarchuk, K. A.: Ionospheric Precursors of Earthquakes, Springer, Berlin, 2004.

Sorokin, V. M., Chmyrev, V. M., and Isaev, N. V.: A generation model of small-scale geomagnetic field-aligned plasma inhomogeneities in the ionosphere, J. Atmos. Solar-Terr. Phys., 60, 1331-1342, 1998.

Sorokin, V. M. and Chmyrev, V. M.: Modification of the ionosphere by seismic related electric field, in: Atmospheric and Ionospheric Electromagnetic Phenomena Associated with Earthquakes, edited by: Hayakawa, M., Terra publication, Tokyo, 805818, 1999.

Sorokin, V. M., Chmyrev, V. M., and Yaschenko, A. K.: Possible DC electric field in the ionosphere related to seismicity, Adv. Space Res., 37, 666-670, 2006.

Zhang, X., Zeren, Z., Parrot, M., Battiston, R., Qian, J., and Shen, X.: ULF/ELF ionospheric electric field and plasma perturbations related to Chile earthquakes, Adv. Space Res., 47, 991-1000, 2011. 